\title{
VARIATION OF RADIOCARBON CONTENT IN TREE RINGS DURING THE MAUNDER MINIMUM OF SOLAR ACTIVITY
}

\author{
G. E. KOCHAROV, A. N. PERISTYKH
}

A. F. Ioffe Physical-Technical Institute, St. Petersburg 194021 Russia

P. G. KERESELIDZE, Z. N. LOMTATIDZE, R. YA. METSKHVARISHVILI, Z. A. TAGAURI

S. L. TSERETELI and I. V. ZHORZHOLIANI

Tbilisi State University, Tbilisi 380028 Georgia

ABSTRACT. We present here annual data on ${ }^{14} \mathrm{C}$ abundance in tree rings during the Maunder minimum of solar activity
(AD 1645-1715). We show that the solar modulation persisted during the minimum. We also compare these data with
measurements of ${ }^{10} \mathrm{Be}$ concentration in dated polar ice cores and with records of aurorae recurrence during this time interval.

\section{INTRODUCTION}

The use of cosmogenic isotopes provides a unique opportunity to study past solar activity in terms of proxy indices. Available data on the cosmogenic isotopes, ${ }^{14} \mathrm{C}$ and ${ }^{10} \mathrm{Be}$, in dated natural archives allow reliable determination of the level of solar activity over several hundred years (Kocharov et al. 1985). A particular goal of the study of short-term variations of solar activity is to obtain precise radiocarbon data, which is of special importance in the problem of the Maunder minimum of solar activity ( $\mathrm{AD} 1645-1715)$.

During the last 20 years in the USSR, two cycles of high-precision measurements of ${ }^{14} \mathrm{C}$ abundance in tree rings were performed. Vasiliev and Kocharov (1983) reported initial data for even years in the interval, $A D$ 1600-1730. In this effort, pine tree-ring samples were dated using liquid scintillation counting (LSC); the new and unpredicted result concerned the existence of ${ }^{14} \mathrm{C}$ variations during the Maunder minimum. Considering the significance of the problem, we measured a different set of samples from fir tree rings taken from another locality (Zhorzholiani et al. 1988; Kocharov et al. 1990).

\section{METHODOLOGY}

The time series presented in this report depicts annual values of $\Delta^{14} \mathrm{C}$ in dated rings of dead (archaeological) and living fir-tree wood collected in the western Ukraine (Zhorzholiani et al. 1988). Samples for the interval, AD 1600-1650, were taken from an old house in Lvov $\left(50^{\circ} \mathrm{N}\right.$, $\left.24^{\circ} \mathrm{E}\right)$. For $\mathrm{AD} 1665-1699$, samples were collected from a church in Busk $\left(50^{\circ} \mathrm{N}, 25^{\circ} \mathrm{E}\right)$ (Bitvinskas et al. 1988). Tree-ring samples (since AD 1701) were taken from living trees in the Karpaty Mountains near the Goverla peak $\left(48^{\circ} \mathrm{N}, 24^{\circ} \mathrm{E}\right)$. Unfortunately, due to existing uncertainties in dating dead wood, tree-ring measurements revealed a gap of 14 years, from AD 1651 to 1664 .

We dated our samples using LSC, and followed the protocol for the pretreatment of wood samples according to Arslanov (1970). Acetylene was synthesized from lithium carbide in a hand-made chemical unit. Benzene synthesis was performed by cyclotrimerization of acetylene on an aluminosilicate catalyst activated by $\mathrm{Cr}_{2} \mathrm{O}_{3}$; benzene yield was $90-98 \%$.

Each LSC unit was designed as a two-channel system (Kocharov \& Metskhvarishvili 1986). The detectors are surrounded by mercury-iron shielding. Spherical vials for benzene samples are made of potassium-free glass. Measurement precision is $0.2-0.3 \%$. 
Corrections for isotopic fractionation were based on $\delta^{13} \mathrm{C}$ values of benzene. Small benzene samples were completely converted to $\mathrm{CO}_{2}$ by oxygen combustion in a calorimetric bomb designed by Burchuladze et al. (1970). Samples were analyzed by the two-beam bridge method to a precision of $0.03 \%$ in a commercial MI-1305 mass spectrometer.

\section{DISCUSSION}

Figure 1 shows the raw $\Delta^{14} \mathrm{C}$ data for the period, $\mathrm{AD} 1600-1760$. Here we also plotted a curve of the data smoothed by a 3-point moving average procedure, along with a long-term variation curve derived by smoothing a 29-point moving average. We see the ${ }^{14} \mathrm{C}$ increase from $c a . \mathrm{AD} 1650$ to 1720 , as well as short-term variations during the Maunder minimum.

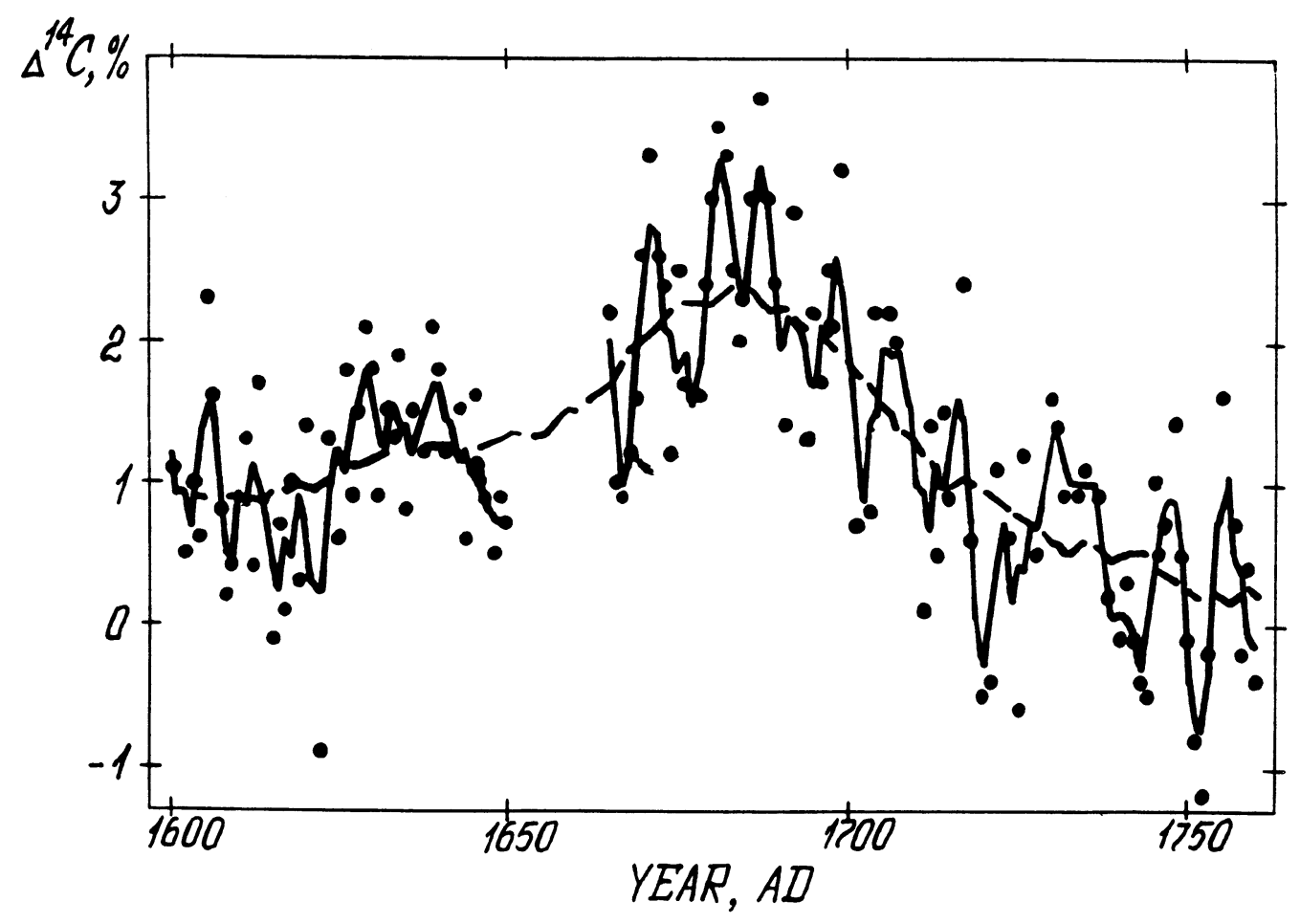

Fig. 1. Variations of $\Delta^{14} \mathrm{C}$ in the annual rings of a fir tree from the western Ukraine, AD 1600-1940: the raw data $(\bullet)$ and the data smoothed by the 3-point (-) and by the 29 -point moving average (- - .

In order to match the short-term variations in both ${ }^{14} \mathrm{C}$ records, we suppressed the long-term trends by first-order difference filtering (Jenkins \& Watts 1968). Before that, in order to obtain the annual record, both sets of data were padded by a linear interpolation procedure. The resultant series for AD 1660-1730, smoothed by a 5-point moving average, is depicted in Figure 2. It is obvious that increases and decreases of both curves fall generally in the same time intervals. Thus, we can note that they are in sufficient agreement; our data confirm the conclusion made by Vasiliev and Kocharov (1983) on the modulation of galactic cosmic radiation by the Sun during the Maunder minimum.

It is important to compare the behavior of short-term variations in our ${ }^{14} \mathrm{C}$ data with that of ${ }^{10} \mathrm{Be}$ data obtained from Greenland ice cores. The data were padded by linear interpolation to obtain the annual record. Here, the long-term trend, derived by smoothing a 29-point moving average, was 


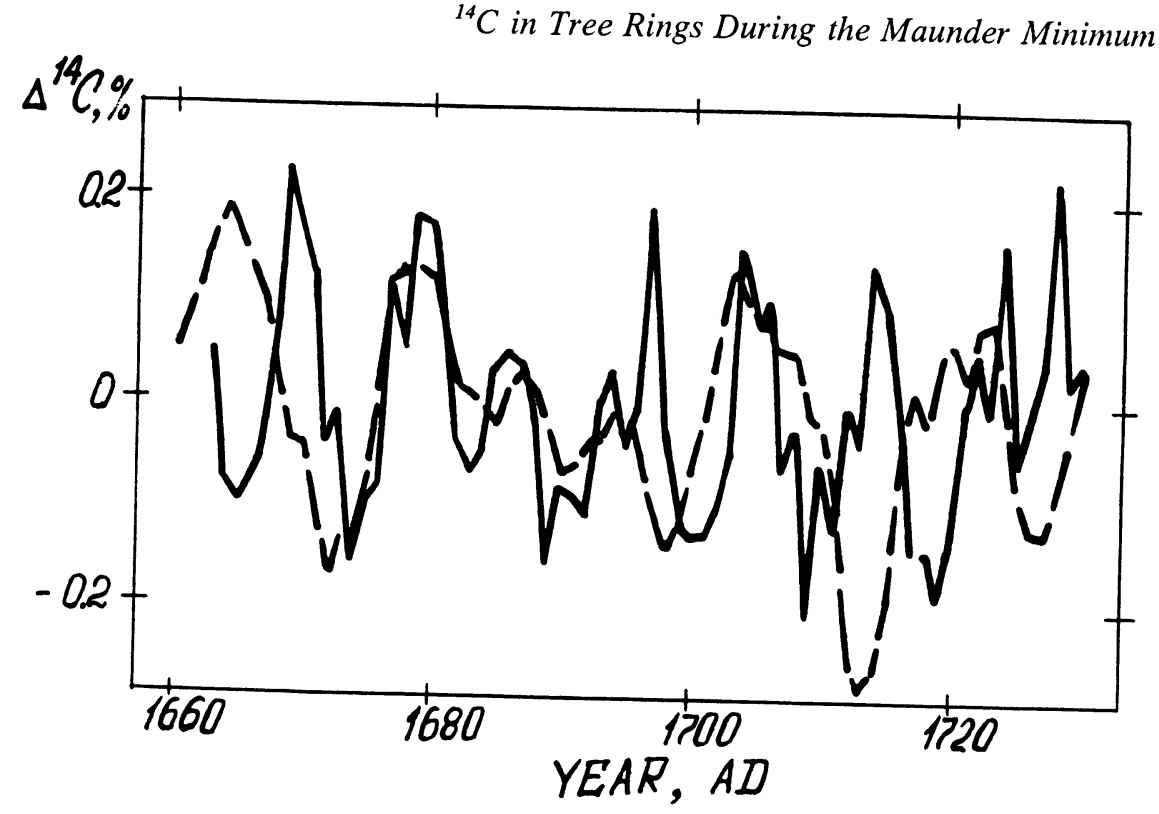

Fig. 2. Short-term variations of $\Delta^{14} \mathrm{C}$ in the annual rings of a fir tree from the western Ukraine, $\mathrm{AD} 1665-1730(-)$ and pine from the southern Ural, AD 1660-1730 (- ) derived by the first-order difference, and then by the 5-point moving
average filtering.

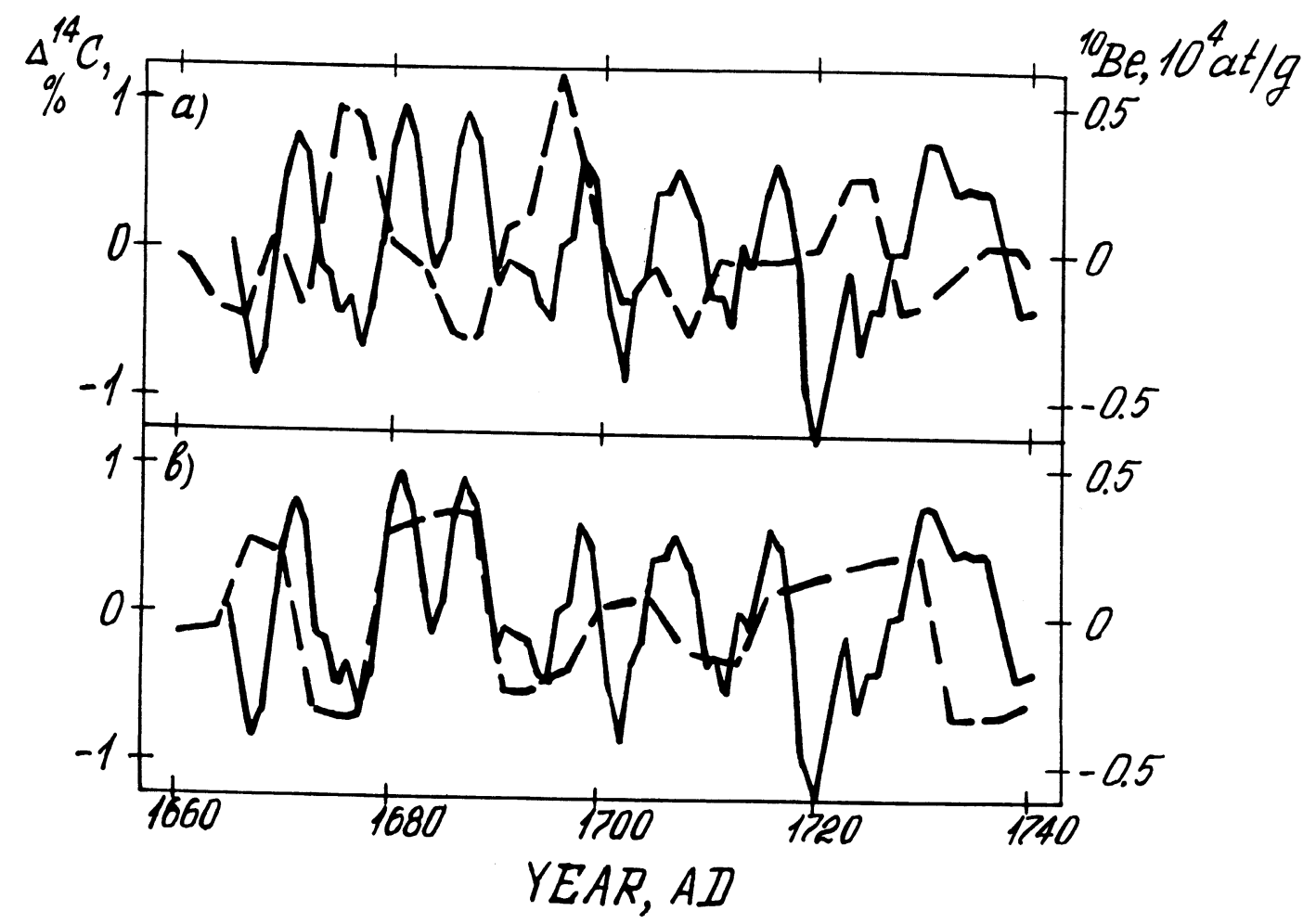

Fig. 3. Short-term variations of $\Delta^{14} \mathrm{C}$ in the annual rings of a fir tree from the western Ukraine, $\mathrm{AD} 1665-1730(-)$ and in the ${ }^{10} \mathrm{Be}$ concentration in Greenland ice cores, $\mathrm{AD} 1660-1740(--)$ from Milcent site (A) and Dye 3 station (B). Data were processed by the subtraction of trends derived by the 29-point moving average, and then by the 3-point moving average smoothing. 
subtracted from all the series under consideration. We chose this method of high-pass filtering, taking into account the noisiness of these signals. Resultant series were smoothed by a 3-point moving average. Figure 3A shows comparison of our data with data for the Milcent core (Beer et al. 1983). Figure 3B displays data for the Camp Century core (Beer et al. 1984) for AD 16601760 , which shows better agreement with the data in Figure 3A. Note, however, that the two ${ }^{10} \mathrm{Be}$ series are not in phase with each other, possibly due to the paleorainfall effect.

We also compared smoothed curves derived by first-order difference filtering, and then by a 3point moving average to observe short-term variations in our ${ }^{14} \mathrm{C}$ series, and in the record of annual recurrence of aurorae borealis over AD 1645-1706 (Schroeder 1988) (Fig. 4). Clearly, the maxima and minima of both curves fall generally in the same time intervals, and their behaviors are in good agreement.

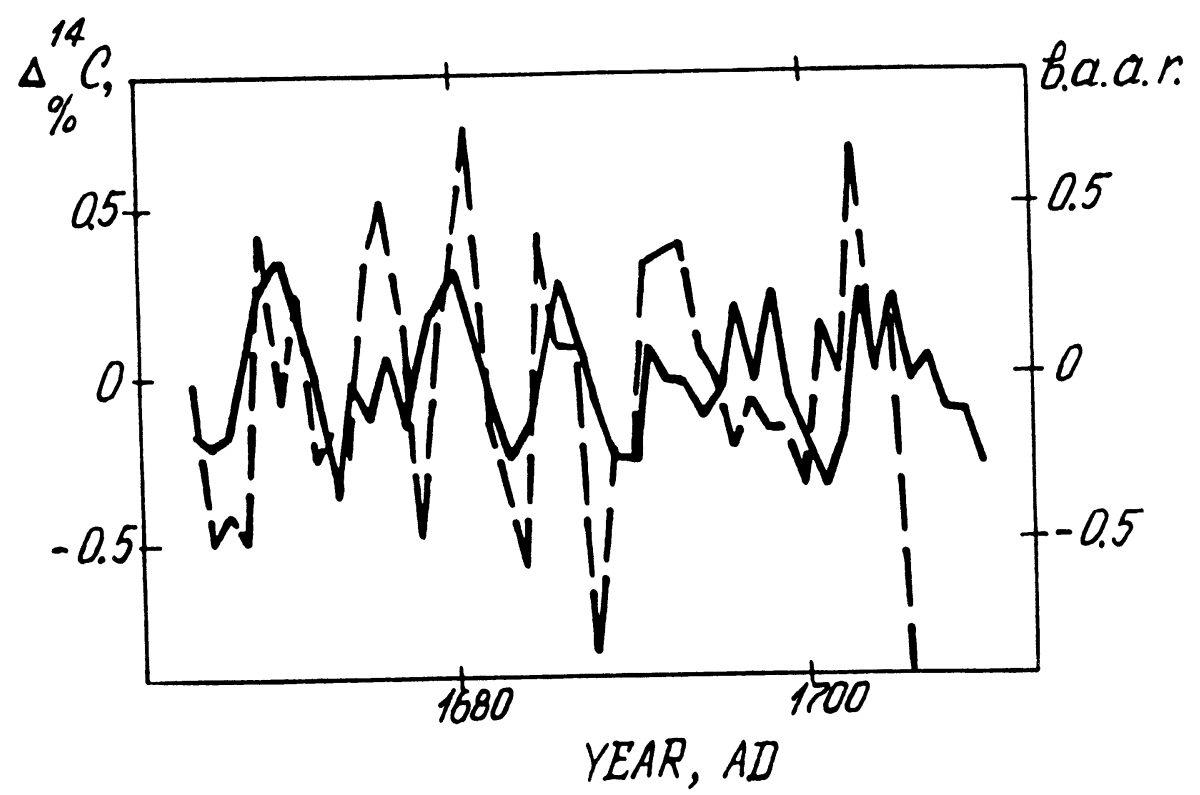

Fig. 4. Short-term variations of $\Delta^{14} \mathrm{C}$ in the annual rings of a fir tree from the western Ukraine, $\mathrm{AD} 1665-1710(-)$ and in the aurorae borealis annual recurrence, $\mathrm{AD}$ 1665-1706 (- -). The first-order difference and the 3-point moving average filtering were used.

\section{CONCLUSIONS}

During the Maunder minimum, radiocarbon abundance in annual tree rings changed over time; this result agrees with data on aurorae borealis recurrence and ${ }^{10} \mathrm{Be}$ variation in polar ice cores. This indicates that the intensity of galactic cosmic radiation is modulated by the Sun, even during conditions of minimal sunspot activity. 


\section{REFERENCES}

Arslanov, Kh. A. 1970 Chemical preparation of tree ring samples for determination of radiocarbon abundance. In Kocharov, G. E., Dergachev, V. A. and Mirianashvili, G. M., eds., Proceedings of the All-Union Consult on the Problem, Astrophysical Phenomena and Radiocarbon. Tbilisi, Tbilisi University Publication Office: $37-40$ (in Russian).

Beer, J., Andrée, M., Oeschger, H., Siegenthaler, U., Bonani, G., Hofmann, H., Morenzoni, E., Nessi, M., Suter, M., Wölfli, W., Finkel, R. C. and Langway, C. C., Jr. 1984 The Camp Century ${ }^{10} \mathrm{Be}$ record: Implications for long-term variations of the geomagnetic dipole moment. In Wölfli, W., Polach, H. A. and Anderson, H. H., eds., Proceedings of the 3rd International Symposium on Accelerator Mass Spectrometry. Nuclear Instruments and Methods B5:380384.

Beer, J., Siegenthaler, U., Oeschger, H., Andrée, M., Bonani, G., Suter, M., Wölfli, W., Finkel, R. C. and Langway, C. C., Jr. 1983 Temporal ${ }^{10} \mathrm{Be}$ variations. Proceedings of the 18th International Cosmic Ray Conference 9: 317-320.

Bitvinskas, T. T., Dergachev, V. A., Kolyshchuk, V. G., Kocharov, G. E. and Chesnokov, V. I. 1988 Tree ring analysis in astrophysical and geophysical investigations. In Kocharov, G. E., ed., Experimental Methods in Research of Astrophysical and Geophysical Phenomena. Leningrad, PhTI Publication Office: 9-55 (in Russian).

Burchuladze, A. A., Togonidze, G. I., Oganezov, P. S. and Pagava, S. V. 1970 The new type unit for the burning of samples for radiocarbon measurements. In Kocharov, G. E., Dergachev, V. A. and Mirianashvili, G. M., eds., Proceedings of the All-Union Consult on the Problem, Astrophysical Phenomena and Radio. carbon. Tbilisi, Tbilisi University Publication Office: 51-53 (in Russian).

Jenkins, J. M. and Watts, D. G. 1968 Spectral Analysis and its Applications. San Francisco, California, Holden-Day: $525 \mathrm{p}$.

Kocharov, G. E., Bitvinskas, T. T., Vasiliev, V. A., Dergachev, V. A., Konstantinov, A. N., Metskhvarishvili, R. Ya., Ostryakov, V. M. and Stupneva, A. V. 1985 Cosmogenic isotopes and astrophysical phenomena. In Kocharov, G. E., ed., Astrophysical Phenomena and Radiocarbon. Leningrad, PhTI Publication Office: 9-142 (in Russian).

Kocharov, G. E. and Metskhvarishvili, R. Ya. 1986 Complex of high sensitivity scintillation $\beta$-spectrometers for measurements of radiocarbon abundance in the Earth's atmosphere. Preprint No. 1003 of A. F. Ioffe Physical-Technical Institute. Leningrad, PhTI Publication Office, 24 p. (in Russian).

Kocharov, G. E., Zhorzholiani, I. V., Lomtatidze, Z. V., Peristykh, A. N., Tsereteli, S. S. L. and Chesnokov, V. I. 1990 On the solar activity characteristics during the past 400 years. Pis'ma $v$ Astronomicheskii Zhurnal 16(8): 723-728 (in Russian).

Schroeder, W. 1988 Aurorae during the Maunder minimum. Meteorology and Atmospheric Physics 38: 246-251.

Vasiliev, V. A. and Kocharov, G. E. 1983 On the solar activity dynamics during the Maunder minimum. In Kocharov, G. E., ed., Proceedings of the 13th International Seminar on Cosmophysics. Leningrad, PhTI Publication Office: 75-100 (in Russian).

Zhorzholiani, I. V., Kereselidze, P. G., Kocharov, G. E., Lomtatidze, Z. V., Marchilashvili, N. M., Metskhvarishvili, R. Ya., Tagauri, Z. A., Tsereteli, S. L. and Chesnokov, V. I. 1988 Measurement of radiocarbon content in tree rings for the period 1600-1940 with corrections for isotopic fractionation. In Kocharov, G. E., ed., Experimental Methods in Research of Astrophysical and Geophysical Phenomena. Leningrad, PhTI Publication Office: 92-113 (in Russian). 